Int. J. Curr. Res. Med. Sci. (2017). 3(6): 98-104

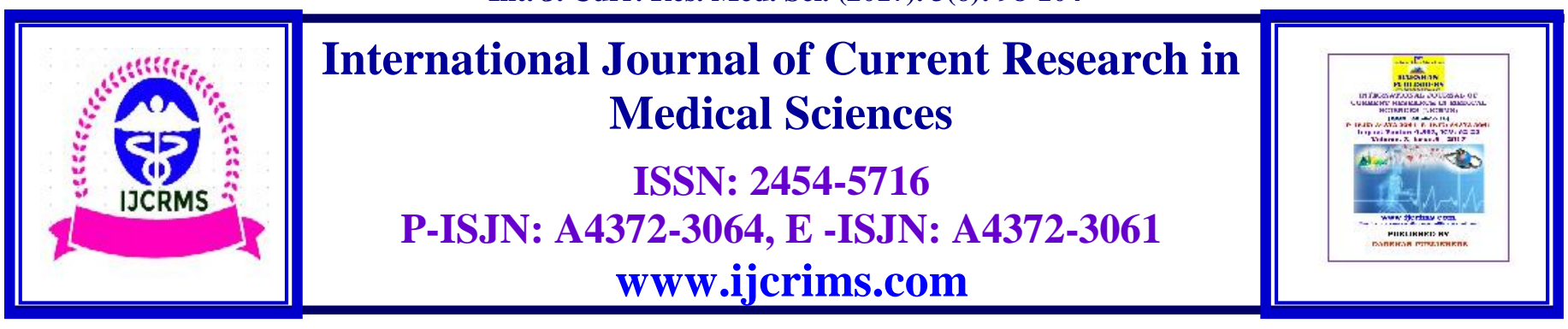

Original Research Article

Volume 3, Issue 6 -2017

DOI: http://dx.doi.org/10.22192/ijcrms.2017.03.06.013

\title{
Prevalence of viral hepatitis in pregnancy: An observational study
}

\author{
*Anita Madan,**Sitara Soni,***Upassana****Aakanksha Dogra,*****N.S.Neki \\ *Assistant Professor **Senior Resident, ***Lecturer, ****Junior Resident,Dept. of Obstetrics and \\ Gynaecology,Govt. Medical College, Amritsar, India, 143001 \\ ******Professor of Medicine, Govt. Medical College, Amritsar, India, 143001 \\ Corresponding Author:Dr. Anita Madan \\ E-mail:dranitapuri@gmail.com
}

\begin{abstract}
Objective: To study the prevalence of viral hepatitis and maternal fetal outcomes in pregnant women with jaundice. Material and Methods: A prospective study was conducted over a period of 6 months in a tertiary care centre of Govt. Medical College ,Amritsar. 63 pregnant women with jaundice were included in this study. All the patients were screened for viral markers, liver function tests, renal function tests and coagulation profile. They were then followed during their hospital stay and the maternal and neonatal outcomes were studied.

Results: The study showed that Hepatitis E virus was the main cause of viral hepatitis in pregnancy in our centre. Most of the patients reported in the third trimester and were primigravidae.

Conclusion: Hepatitis E infection has poor maternal as well as neonatal outcome out of all types of viral hepatitis. As the route of transmission is feco-oral, proper sanitation and clean drinking is the need of the hour. The second important cause of viral hepatitis was infection with Hepatitis $C$ virus. Intravenous drug abuse is the main cause. Therefore, in order to minimise viral hepatitis in pregnant women, complete immunization should be advocated in all women of reproductive age group.
\end{abstract}

Key words: Pregnancy ,Hepatitis E, Hepatitis C, feco-oral route

Keywords: Pregnancy, Hepatitis E, Hepatitis C, feco-oral route

\section{Introduction}

Viral hepatitis is a major public health problem in India which is hyper endemic for Hepatitis A and Hepatitis E virus. In pregnancy, greater morbidity and mortality of hepatitis, especially during epidemics, have been noticed as a consequence of poor prenatal care and malnutrition ${ }^{1-3,12-14}$. Viral hepatitis in pregnancy can lead to coagulation defects, post partum haemorrhage, multi organ failure and high maternal mortality. Neonatal complications such as still birth, neonatal death, acute and chronic liver disease and hepatocellular carcinoma have all been reported. Therefore, early diagnosis and treatment is required for the better management of patients 4 . 
Hepatitis E virus is responsible for worst maternal and fetal outcomes in pregnant women as compared to other types of viral hepatitis ${ }^{5}$. HEV infection is so severe that it often leads to Fulminant Hepatic Failure and mortality may go upto $75 \%{ }^{3}$. Hepatitis $\mathrm{E}$ virus (HEV) infection is the major cause of outbreaks and acute sporadic hepatitis worldwide. HEV infecting humans consists of four different genotypes (genotype 14), with several sub genotypes in each. However, only one single HEV serotype was recognized. $\mathrm{HEV}$ genotypes 1 and 2 are found mainly in developing countries.

$\mathrm{HEV}$ is responsible mainly for outbreaks in developing countries and sporadic cases in the western world ${ }^{6}$. HEV outbreaks have been reported from 12 countries all over the world that include Indonesia, Myanmar, Vietnam, Japan, China, Bangladesh ${ }^{7,8}$, Pakistan, Nepal, Iraq, Uzbekistan, Turkmenistan, and India. India represents a country with the highest number of reported HEV outbreaks. HEV genotypes 1 and 2 were responsible for most of the large outbreaks in developing countries. During the outbreaks in developing countries, a significantly higher case fatality rate was observed in pregnant women.

It is estimated that $\mathrm{HEV}$ is responsible for $\sim 9.8 \%$ of pregnancy-associated deaths in Bangladesh and about 10,500 of annual maternal death in southern Asia. Some immunological and hormonal factors have been associated with high mortality rate in HEV-infected pregnant women ${ }^{9}$. Therefore, interventions to prevent the occurrence of $\mathrm{HEV}$ infections in the high-risk populations are urgently required.

\section{Materials and Methods}

This study was conducted in sixty three antenatal inpatients having jaundice in a tertiary hospital of Govt. Medical College Amritsar over a period of 6 months. Prevalence of different types of viral hepatitis in pregnancy was studied.

\section{Inclusion criteria:}

Pregnant women having jaundice

Pregnant women with serologically positive cases of viral hepatitis.

\section{Exclusion criteria:}

Severe PIH with HELLP syndrome.

Acute fatty liver

Drug hepatitis

Patients with negative serology

Intrahepatic cholestasis of pregnancy.

Chronic liver disease.

Baseline investigations i.e. $\mathrm{CBC}$, Liver function tests, coagulation profile and serological tests were carried out. All the patients were followed throughout pregnancy and intrapartum period. Complications, both maternal and neonatal were recorded. The data was then statistically analysed.

\section{Results}

63 pregnant women with mean age $25 \pm 7.07$ years presented with clinical and biochemical evidence of hepatitis. These women were serologically proven cases of viral hepatitis. Majority were from rural area and were from low socioeconomic strata. $90 \%$ of the patients were emergency admissions and $10 \%$ were booked. 
Int. J. Curr. Res. Med. Sci. (2017). 3(6): 98-104

Table 1: Demographic profile

\begin{tabular}{|c|l|c|c|}
\hline Parameter & & No. of patients & Percentage \\
\hline 1.Age & & & \\
\hline & $<20$ years & 4 & $6.34 \%$ \\
\hline & $20-24$ years & 22 & $34.9 \%$ \\
\hline & $25-29$ years & 32 & $50.7 \%$ \\
\hline & $>30$ years & 5 & $7.94 \%$ \\
\hline & & 25 & $39.68 \%$ \\
\hline & Primigravida & 16 & $25.3 \%$ \\
\hline & Second gravida & 20 & $31.74 \%$ \\
\hline & Third gravida or more & 2 & $3.17 \%$ \\
\hline & Postpartum & & \\
\hline 3.Duration of pregnancy & & 2 & $3.17 \%$ \\
\hline & First trimester & 8 & $12.69 \%$ \\
\hline & Second trimester & 51 & $80.95 \%$ \\
\hline & Third trimester & 2 & $3.17 \%$ \\
\hline & Postpartum & &
\end{tabular}

Table 1 shows that $32(50.7 \%)$ patients were in the age group of $25-29$ years of age,22 (34.9\%) were in the age group of $21-24$ years , $4(6.34 \%)$ were less than 20 years old and $5(7.94 \%)$ were more than 30 year old. Out of 63 women, 25(39.68\%) were primigravidae, $20(31.74 \%)$ were third gravid or more, $16(25.3 \%)$ were second gravidae and $2(3.17 \%)$ were in the post partum period. $51(80.95 \%)$ women reported to us in the third trimester, $8(12.69 \%)$ in the second trimester, 2 $(3.17 \%)$ in the first trimester and $2(3.17 \%)$ in the post partum period.

Table 2: Viral markers

\begin{tabular}{|c|c|c|}
\hline Etiology & No. of patients & Percentage \\
\hline HAV & 4 & $6.34 \%$ \\
\hline HbsAg & 13 & $20.63 \%$ \\
\hline HCV & 20 & $31.74 \%$ \\
\hline HEV & 24 & $38.09 \%$ \\
\hline HBsAg+HEV & 2 & $3.17 \%$ \\
\hline
\end{tabular}

Table 2 shows that the aetiologies of acute viral hepatitis were HAV in 4 patients $(6.34 \%) \mathrm{HBsAg}$ in $13(20.63 \%) \mathrm{HCV}$ in $20(31.74 \%)$, HEV in
24(38.09\%) and HBsAg+ HEV were seen in $2(3.17 \%)$.

Table 3: Maternal morbidity

\begin{tabular}{|c|c|c|}
\hline Complication & Frequency & Percentage \\
\hline Fulminant Hepatic Encephalopathy & 11 & $17.46 \%$ \\
\hline Coagulopathy & 2 & $3.17 \%$ \\
\hline Post partum hemorrhage & 5 & $7.93 \%$ \\
\hline Acute renal failure & 1 & $1.59 \%$ \\
\hline Maternal death & 4 & $6.35 \%$ \\
\hline
\end{tabular}


Int. J. Curr. Res. Med. Sci. (2017). 3(6): 98-104

Table 3 shows that $11(17.46 \%)$ patients developed fulminant hepatic encephalopathy, $2(3.17 \%)$ patients developed coagulopathy,
$5(7.03 \%)$ patients developed post partum hemorrhage , 1 (1.59\%) patient developed acute renal failure and $4(6.35 \%)$ patients died.

Table 4: Maternal outcome

\begin{tabular}{|c|c|c|}
\hline outcome & no. of patients & percentage \\
\hline Vaginal delivery & 49 & $77.78 \%$ \\
\hline Cesarean section & 10 & $15.87 \%$ \\
\hline Spontaneous abortion & 4 & $6.35 \%$ \\
\hline
\end{tabular}

Table 4 shows that out of the 63 patients, $49(77.78 \%)$ had a normal vaginal delivery,
(10) $15.87 \%$ underwent a cesarean section and (4) $6.35 \%$ had spontaneous abortion

Table 5: Neonatal outcome

\begin{tabular}{|c|c|c|}
\hline Outcome & No.of cases & Percentage \\
\hline Preterm delivery & 12 & $19.04 \%$ \\
\hline IUD & 15 & $23.80 \%$ \\
\hline Live births & 32 & $50.79 \%$ \\
\hline
\end{tabular}

Table 5 shows that out of the 59 patients, 12 (9.04\%) patients delivered a preterm baby, $15(23.80 \%)$ delivered a dead fetus and $32(50.79 \%)$ delivered healthy full term alive babies.

\section{Discussion}

In this prospective study of 63 pregnant women with jaundice and acute viral hepatitis admitted to our centre, we found that HEV infection accounted for $38.09 \%$ of cases. This is comparable with the observation of Jaiswal et al from India and Aziz et al from Pakistan who reported an incidence of 58 and $62 \%$ respectively $^{11,12}$. Acute Hepatitis $\mathrm{E}$ infection during the third trimester of pregnancy is the cause of fulminant hepatic failure and has morbidity rate of up to $45.8 \%$ in our study which is comparable to Jaiswal et al and Beniwal et al ${ }^{3,11}$ .Out of 63, most commonly affected were 20 to 29 years of age with mean age of $25 \pm 7.07$ years as was seen in the study by Patra et al and Shukla et $\mathrm{al}^{4,10}$.
Most of the women were primigravidae (39.68\%) and many of them were in the third trimester $(80.95 \%)$. The obstetrical and neonatal outcome in HEV infection in pregnant women was not favourable as reported in other studies ${ }^{13}$. Out of 24 of HEV seropositive patients, 11(45.8\%) developed hepatic encephalopathy, out of them 4 patients died. These findings are similar to another study by Khuroo et al ${ }^{13}$. An important observation made in present study was occurrence of coagulopathy and post partum haemorrhage in $3.17 \%$ and $7.93 \%$ of cases respectively, more so in $\mathrm{HEV}$ positive which was comparable to the number reported by Khuroo et $\mathrm{al}^{13}$.

Out of $24 \mathrm{HEV}$ infected women, 12 delivered a preterm baby, 15 cases delivered a dead fetus and 32 cases delivered a full term alive baby. The reason behind high perinatal mortality in HEV is still not clear. It may be due to vertical transmission from mother to fetus, preterm delivery and low birth weight babies ${ }^{13,14}$. 
Prevalence of HAV infection was $6.34 \%$ and HBsAg infection was $20.63 \%$ in the present study which is consistent with other Indian studies done by Beniwal and Singh et $\mathrm{al}^{3,15}$. In $3.17 \%$ patients HBsAg and HEV co existed.

In patients with acute hepatitis $B$, vertical transmission was seen in up to $10 \%$ of neonates when infection occured in the first trimester and in $80-90 \%$ of neonates when acute infection occured in the third trimester. In women who were seropositive for both $\mathrm{HBsAg}$ and $\mathrm{HBeAg}$ vertical transmission was approximately $90 \%$. 10$20 \%$ of women seropositive for $\mathrm{HBsAg}$ transmitted the virus to their neonates in the absence of immunoprophylaxis.

Immunoprophylaxis failure against vertical transmission appears to occur more frequently in mothers who are $\mathrm{HBeAg}$-positive and or who have a high viral load. Although the presence of $\mathrm{HBeAg}$ generally indicates high levels of virus and greater infectivity, the absence of e-antigen does not exclude active viral replication. Maternal HBV-DNA level has been demonstrated to be the strongest predictor of neonatal immunoprophylaxis failure, with a lower effective rate being directly related to a higher maternal viral load.

Chronic infection occurs in about $90 \%$ of infected infants, $30 \%$ of infected children aged $<5$ years , and $2 \%-6 \%$ of adults. Among persons with chronic HBV infection, the risk of death from cirrhosis or hepatocellular carcinoma is $15 \%$ $25 \%$.

The prevalence of $\mathrm{HCV}$ infection in our study was $31.74 \%$ which was higher as compared to other studies ${ }^{16,17}$. Earlier studies have found an association between the prevalence of $\mathrm{HCV}$ infection and known risk factors of this infection .i.e., blood transfusion, intravenous drug abuse, multiple sexual partners and homosexuality 16,17 . The prevalence is maximum in individuals of reproductive age. This may be because of the high prevalence of $\mathrm{HCV}$ infection in Punjab due to high rate of drug addiction, though no studies are available till date.
As the HEV infection in pregnant patients leads to high mortality, therefore, interventions to prevent the occurrence of HEV infections in the high-risk populations are therefore urgently required. Since HEV outbreak is mainly due to contaminateddrinking water, its control would depend upon improved hygiene and sanitation, such as increased access to safe water, provision of soap and chlorine tablets to improve personal hygiene, and proper sewage disposal.

During outbreak, it is necessary to intensively investigate the suspected underlying cause and then initiate targeted intervention to control and stop the outbreak. Mass vaccination of HEV could be another effective method to control the outbreaks. Currently, an HEV vaccine has already been licensed for use in China which gives an idea that HEV is a vaccine-preventable disease. Comparing the experience with HAV vaccination as an effective measure to control HAV outbreaks, the HEV vaccine holds promises to control large outbreaks.

However, it is not known whether the current vaccine works fast enough to effectively protect the exposed population against the disease during an HEV outbreak. Moreover, it is also not known whether the vaccine is safe and effective in pregnant women, the population in which a high fatality rate was seen during the outbreak. In fact, there is a disagreement among the HEV experts on whether the current licensed vaccine is necessary to prevent outbreak, following the recent earthquake in Nepal ${ }^{18,19}$.

\section{Conclusion}

Acute viral hepatitis is the most common cause of jaundice in pregnancy with $\mathrm{HEV}$ infection being the most predominant cause. Maternal and perinatal morbidity and mortality are maximum in HEV infection. Cleanliness, construction of toilets and availability of clean drinking water to the population will improve the sanitary conditions of our rural areas. This will go a long way in minimising HAV and HEV infection. Judicious 
use of blood and blood products is very important. Blood should be transfused only in dire emergencies. Substance abuse needs to be addressed as this is the main mode of transmission of Hepatitis B and C. Unwarranted intravenous infusions and injections given by the quacks in rural areas needs to be curbed. People should be educated regarding the parentral mode of transmission in hepatitis B, C and D infections. Safe sexual practices should be advocated. Effective immunization should be done against Hepatitis A and B in women of reproductive age group.

\section{Source of funding: Nil}

\section{Conflict of interest: None declared}

\section{References}

1. Almashhrawi AA, Ahmed KT, Rahman RN, Hammond GN, Ibdah JA, Liver diseases in pregnancy: diseases not unique to pregnancy. World J Gastroenterol. 2013;19(43):7630-8.

2. Khuroo MS, Kamili S. Aetiology, clinical course and outcome of sporadic acute viral hepatitis in pregnancy. J Viral Hepat. 2003;10(1):61-9.

3. Beniwal M, Kumar A, Kar P,N Jilani, JB Sharma, Prevalence and severity of acute viral hepatitis and fulminant hepatitis during pregnancy: a prospective study from north India. Indian J Med Microbiol. 2003;21(3):184-5.

4. Suruchi Shukla, Geeta Mehta.A Prospective Study on Acute Viral Hepatitis in Pregnancy; Seroprevalence, and Fetomaternal Outcome of 100 cases, J Biosci Tech, Vol 2 (3),2011,279286

5. Yang YB, Li XM, Shi ZM, Ma L. Pregnant woman with fulminant hepatic failure caused by hepatitis B virus infection: A case report. World J Gastroenterol 2004;10(15):23052306.

6. Kim JH, Nelson KE, Panzner U, Kasture Y, Labrique AB, Wierzba TF. A systematic review of the epidemiology of hepatitis $E$ virus in Africa. BMC Infect Dis. 2014;14:308.
7. Gurley ES, Hossain MJ, Paul RC, Sazzad HMS, Islam MS,Shahana Parveen et al Outbreak of hepatitis E in urban Bangladesh resulting in maternal and perinatal mortality. Clin Infect Dis. 2014;59:658-665.

8. Harun-Or-Rashid M, Akbar SMF, Takahashi K, Mamun Al-Mahtab, Mohammad Sakirul Islam Khan, Alim MA et al Epidemiological and molecular analyses of a non-seasonal outbreak of acute icteric hepatitis $\mathrm{E}$ in Bangladesh. J Med Virol.2013;85:13691376.

9. Sehgal R, Patra S, David P, Vyas A, Khana A, Hissar $S$ et al Impaired monocyte-macrophage functions and defective toll-like receptor signaling in hepatitis $\mathrm{E}$ virus-infected pregnant women with acute liver failure. Hepatology. 2015;62:1683-1696.

10. Patra S, Kumar A, Trivedi SS, Puri M, Sarin SK. Maternal and fetal outcomes in pregnant women with acute hepatitis E virus infection. Ann Intern Med 2007;147:28-33.

11. Jaiswal SP, Jain AK, Naik G,N. Soni, D.S. Chitnis. Viral hepatitis during pregnancy. Int J Gynaecol Obstet. 2001;72(2):103-8

12. Aziz AB, Hamid S, Iqbal S, Islam W, Karim SA. Prevalence and severity of viral hepatitis in Pakistani pregnant women: a five year hospital based study. J Pak Med Assoc. 1997;47(8):198-201.

13. Khurro MS, Kamili S, Jameel S: Vertical transmission of hepatitis $\mathrm{E}$ virus.1995 Apr 22;345(8956):1025-6

14. Khuroo .MS, Kamili S. Aetiology, clinical course and outcome of sporadic acute viral hepatitis in pregnancy. J Viral Hepat. 2003;10:61-9.

15. Singh S, Mohanty A, Joshi YK, Deka D, Mohanty S, Panda SK.Mother-to-child transmission of hepatitis $\mathrm{E}$ virus infection. Indian J Pediatr. Jan 2003;70(1):37-9.

16. SilvermanNS,JenkinBK, $\mathrm{Wu} \mathrm{C}$, Meigilennen P. Knee C Hepatitis virus in pregnancy; seroprevalence and risk factors for infection Am J Obstet Gynecol 1993; 169:583-7

17. Marranconi F, Fabris P, Stecca C, Zampieri L,Benini MC, Di Fabrizio N, et al. Prevalence of anti $\mathrm{HCV}$ and risk factors for hepatitis $\mathrm{C}$ virus infection in healthy pregnant women.Infection (1994) 22:333 
18. Basnyat B, Dalton HR, Kamar N, Rein DR, Labrique A, Farrar A, et al. Nepali earthquakes and the risk of an epidemic of hepatitis E. Lancet. 2015;385:2572-2573.

19. Shrestha A, Lama TK, Gupta BP, Sapkota B, Adhikari A,Khadka S et al. Hepatitis E virus outbreak in postearthquake Nepal: is a vaccine really needed? J Viral Hepat. 2016;23:492.

\begin{tabular}{|c|l|}
\hline \multicolumn{2}{|c|}{ Access this Article in Online } \\
\hline & Website: \\
\hline & www.ijcrims.com \\
\hline Quick Response Code & Subject: \\
\hline
\end{tabular}

How to cite this article:

Anita Madan, Sitara Soni, Upassana, Aakanksha Dogra, N.S.Neki. (2017). Prevalence of viral hepatitis in pregnancy: An observational study. Int. J. Curr. Res. Med. Sci. 3(6): 98-104.

DOI: http://dx.doi.org/10.22192/ijcrms.2017.03.06.014 